\title{
The Psychometric Properties of Customer Relationship Management Framework in the Local Government Authorities in Zimbabwe
}

\author{
Douglas Chiguvi ${ }^{1 *}$, Collen Mahambo ${ }^{2}$
}

\begin{abstract}
${ }^{1}$ Senior Lecturer: Marketing Programmes, Entrepreneurship Department, BA ISAGO University P. Bag 149, Gaborone, BOTSWANA
${ }^{2}$ Accounting and Finance Lecturer- BA ISAGO University, P. Bag 149, Gaborone, BOTSWANA

*Corresponding Author: douglas.chiguvi@baisago.ac.bw
\end{abstract}

Citation: Chiguvi, D. and Mahambo, C. (2020). The Psychometric Properties of Customer Relationship Management Framework in the Local Government Authorities in Zimbabwe. Dutch Journal of Finance and Management, 4(2), em0069. https://doi.org/10.21601/djfm/9354

\section{ARTICLE INFO}

Received: 1 Aug. 2020

Accepted: 11 Oct. 2020

\begin{abstract}
Although a lot of empirical studies have been conducted on customer-relationship-management (CRM), little research on the exploration of the psychometric properties of CRM scale items, in the Zimbabwean context has been conducted. This empirical study, based on key informant data drawn from sampled local government authorities in Zimbabwe (LGAZ), developed a reliable scale with demonstrated content and convergent validity. Amongst some of the reliable and valid antecedents and consequences of CRM Strategy success the study found; Due diligence, Strategy focus and alignment, Customer focus, Change management, Implementation Strategy, Implementation approach, Metrics, Project management, Process design, Buy-in and adoption to be some of the most important.. Therefore, using the confirmatory factor analysis approach, the research findings offer one more robustness in the applicability of CRM scale items by confirming that CRM city managers use psychometrically valid scale items to generate, disseminate and respond to information with a view to improving CRM performance of LGAZ.
\end{abstract}

Keywords: psychometric properties of CRM, factor analysis approach, local government authorities, customer relationship management

\section{INTRODUCTION}

Jaiyeoba (2013) asserts that the development of coherent, robust and generalizable theories requires a base of welldefined constructs. Though much empirical studies have been conducted on customer-relationship-management (CRM), little research on the exploration of the psychometric properties of CRM scale items, in the Zimbabwean context has been conducted. This empirical study, based on key informant data drawn from sampled local government authorities in Zimbabwe (LGAZ), developed a reliable scale with demonstrated content and convergent validity. This research therefore proposes to investigate the reliability and validity of the critical success factors (CSFs) in CRM Strategy success in the LGAZ. A reliable scale with demonstrated content and convergent validity is developed and evaluated based on key informant data drawn from sampled LGAZ. Gilliam and Voss (2013), and Grattan (2012) claimed that the foundation of researchers expending the necessary resources to properly define constructs during early stages of research projects, will be strong and able to support expansive theories. Gilliam and Voss also established that construct definitions prevent scientific discussion from devolving into babel thus, the process of construct definition is crucial and a complex task facing marketing researchers not only in the developed world, but also in the emerging markets. Thus, the main objective of this paper sought to investigate the psychometric properties of critical success factors in CRM Strategy in the LGAZ using Confirmatory Factor analysis Approach.

\section{LITERATURE REVIEW}

Churchill (1979), and Bagozzi and Foxall (1995A) ascribe to a scale as having content validity, if the scale-items form a representative sample of the theoretical domain of the construct. Babin and Svensson (2012), accordingly, identified the year 1979, as being the breakthrough year from the paradigm of single-item structures and metric measures, along with the lack of reliability estimates of used constructs in marketing research to a change towards the use of multi-item structures and metric measures and reliability theory in marketing research of human perception, behaviour or phenomenon. Henceforth, the reliability concept was adopted as a routine part of the results sections of marketing research 
articles. Actually, Churchill (1979) transcribed about an emerging paradigm for developing measures of marketing constructs, while Peter (1979) quoted in Babin and Svensson (2012), presented a reliability review of psychometric basics and marketing practices. Undoubtedly, many projects otherwise thought to be well executed, fail to have the impact they should due to poor construct definitions (Churchill, 1979). Bearden and Netemeyer (1999), thus provided widespread reviews of numerous multi-item structures and metric measures in present marketing research literature that have considered the estimates of validity and reliability. Hence, the goal of measurement development is to produce useful and meaningful tools for describing and explaining the phenomena. This experiential research consequently lends credibility to the need for measurement development. Three criteria are considered by psychometricians in their valuation of the quality of measures. The first being the unidimensionality of the scale, which measures the degree that the items in the scale load on a single factor, Gerbing and Anderson (1988). This aspect of a measurement is imperative since, theory development and testing need that a single idea be represented by the measure to allow for subsequent testing for correlations with other constructs or differences between groups. Reliability is the second aspect of good measures, of which this characteristic according Rust and Cooil, (1994), deals with the stability of the measures over time and the internal consistency of answers on measures containing multiple-items. This experiential study, therefore, examines the content validity, coefficient alpha, dimensionality, focusing on the coherence or inter-relatedness of the psychometric properties of CRM items in Zimbabwe. The third indicator of a strong measures is validity which is the degree to which the measure represents the construct domain (Churchill, 1979). Thus, at the center of repeatability and standardization are the measurement properties of reliability and validity, that this study intends to clarify.

Mowen and Voss (2008), and Rossiter (2002), analogously proposed that other authors suggested that researcher concentration on operationalization and statistical analysis distracted attention from construct definition. This claim created the need for this empirical study amongst LGAZ. Gilliam and Voss, (2010), thus theorized that a contributing factors are the lack of understanding of implementable construct definition processes within the extant psychometric literature. Mackenzie (2003), thus suggested that poor construct conceptualization and definition plagues many manuscripts submitted for review. Mackenzie (2003) highlighted the impossibility of accurately specifying theoretical relations between two constructs that lack exact meanings. Summers (2001) resolved that the development of coherent, robust and generalizable theory entails a base of well-defined constructs. Hunt (1991), and Teas and Palan (1997) accordingly suggested the use of formalized language in definitions to reduce ambiguity and vagueness in psychometric competence. On the other hand, Williamson (1994), suggested that while the use of formalized language may facilitate some aspects of the construct definition effort, it introduces a number of problems that have prevented its widespread adoption. However, Rossiter (2002) refuted this psychometric paradigm, by suggesting that being far more specific in regard to the time and place where the construct is applicable will help in construct definition.

\section{RESEARCH METHODOLOGY}

Psychometric Nomenclature analysis was used to check for the accuracy of the questionnaire. In this study, confirmatory factor analysis (CFA) was employed using the Amos 18 version and the SPSS version 20 softwares. Cronbach's Alpha and Kaiser-Meyer-Olkin (KMO) were used to scrutinize for the sufficiency, consistency, intensity and suitability of the questionnaire. The Bartlett Test was also employed to check whether the correlation matrixes of the constructs had significant information while KMO was conducted in order to check whether the pointers of a construct belong together. Reliability analysis was conducted on all the multi-item scales of the measurement instrument to validate the reliability of the measurement instrument. In this study Cronbach's alpha was calculated in terms of the normal inter-correlations among the item evaluating the perception. According to Nunnally and Bernstein (1978) the accepted cut off point is 0.5 for Cronbach's Coefficient to attest that the measurement items are reliable. This assertation was also confirmed by (Jaiyeoba, 2013). This research considers the Cronbach's alpha of 0.50 as reliable. The study confirms that all the measurement items were above 0.50 and this mean the items were reliable to measure the CSFs in CRM Strategy in the local government authorities in Zimbabwe. Uni-dimensionality of 0.30 was measured in order to check the factor loading of the measurement constructs whether they meet the accepted criterion. In this study all the factor loadings depicted in Table 1 meet benchmark of larger than 0.30 and this means that all the CRM items of the study satisfy the Uni-dimensionality requirement. The mean and standard deviation score of each measurement constructs in the questionnaire was also displayed. The outcomes of factor loading, Eigen value, variance, KMO, Bartlett test, mean and standard deviation were illustrated in Table 1.

\section{DATA RESULTS}

\section{Analysis and Discussion}

Confirmatory factor analysis using AMOS 18 version was steered to observe the underlying factors needed for the victory of the CRM Strategy in the LGAZ. In an effort to establish whether the measures retained construct validity (i.e. measure what they were supposed to), a confirmatory factor analysis using principal components and varimax rotation technique was conducted to examine the underlying dimension of critical success factors of CRM Strategy. In ascertaining the critical success factors, common decision rules used in empirical research were applied: minimum Eigen value of 1 ; KMO measure of sampling adequacy greater than 0.5 and Bartlett's test of Sphericity are significant, that indicate the appropriateness of the factor analysis. Table 1 thus shows the validation of the measurement models and analysis of the test for the distinctiveness of internal and external antecedents of CRM. This empirical study therefore 
Table 1. Psychometric Properties of Critical Success Factors in CRM Strategy in the local government authorities in Zimbabwe

\begin{tabular}{|c|c|c|c|c|c|c|}
\hline & $\begin{array}{l}\text { Factor } \\
\text { loading }\end{array}$ & Eigenvalue & $\begin{array}{c}\% \\
\text { eariance } \\
\end{array}$ & $\begin{array}{c}\text { KMOrtlett } \\
\text { Test }\end{array}$ & Mean & $\begin{array}{r}\text { Standard } \\
\text { Deviation }\end{array}$ \\
\hline Critical success factor 1: Due Diligence (DDT) $\alpha=0.506$ & & 2.496 & 62.406 & 0.573305 .055 & & \\
\hline Rigorous planning is done in advance prior to CRM Strategy implementation & 0.459 & & & & 3.507 & 0.502 \\
\hline Customer analysis is done before CRM Strategy implementation. & 0.468 & & & & 2.610 & 0.603 \\
\hline CRM goals are communicated to all stakeholders before CRM Strategy implementation. & 0.819 & & & & 2.760 & 0.678 \\
\hline Due diligence is done before CRM software and vendor selection & 0.849 & & & & 2.952 & 0.881 \\
\hline Critical success factor 2: Strategic Focus \& Alignment (SFAT) $\alpha=0.749$ & & 3.612 & 60.195 & 0.718781 .845 & & \\
\hline Council strategies are aligned in the CRM Strategy & 0.774 & & & & 3.447 & 1.032 \\
\hline Top managers are only involved in formulating CRM Strategy & 0.716 & & & & 3.564 & 1.259 \\
\hline Multidisciplinary teams are created when formulating CRM Strategy & 0.846 & & & & 2.498 & 0.660 \\
\hline $\begin{array}{c}\text { There is a network in order to identify and share best CRM practices among employees } \\
\text { and other stakeholders }\end{array}$ & 0.778 & & & & 2.822 & 1.090 \\
\hline $\begin{array}{c}\text { There are good partnership and harmonization between front and back office units of } \\
\text { council authorities }\end{array}$ & 0.841 & & & & 2.990 & 1.216 \\
\hline CRM Strategy information is shared between different departments of the council & 0.772 & & & & 3.244 & 1.499 \\
\hline $\begin{array}{l}\text { Critical success factor 3: Customer Focus } \\
\text { (CFT) } \alpha=0.884\end{array}$ & & 3.460 & 69.203 & 0.5221097 .89 & & \\
\hline Customers are well-versed about services, products, and other facilities in council & 0.887 & & & & 3.355 & 1.067 \\
\hline Customers' information are wholly assembled in a Database & 0.884 & & & & 2.421 & 0.875 \\
\hline Complaints and propositions of customers are congregated in a database & 0.943 & & & & 2.624 & 1.246 \\
\hline $\begin{array}{l}\text { The collected information and data are scrutinized to solve their problem and service } \\
\text { quality }\end{array}$ & 0.920 & & & & 2.442 & 1.094 \\
\hline $\begin{array}{c}\text { Different tools like Emails, Blogs, and Social media are utilized to communicate to } \\
\text { customers as well as deliver on-line services }\end{array}$ & 0.874 & & & & 3.442 & 0.835 \\
\hline Critical success factor 4: Change Management (CMT) $\alpha=0.858$ & & 3.886 & 64.771 & 0.5221287 .83 & & \\
\hline $\begin{array}{l}\text { All the employees and managers are totally trained, in order to lessen resistance to } \\
\text { change }\end{array}$ & 0.862 & & & & 2.939 & 0.951 \\
\hline $\begin{array}{l}\text { All the employees and managers are fully trained to use CRM software, they are familiar } \\
\text { with CRM Strategy }\end{array}$ & 0.800 & & & & 2.609 & .872 \\
\hline There is a robust CRM oriented culture in the council & 0.963 & & & & 3.772 & 1.052 \\
\hline $\begin{array}{l}\text { Incentives like motivation, reward, and recognition are provided to encourage CRM } \\
\text { Strategy implementation. }\end{array}$ & 0.609 & & & & 2.843 & .821 \\
\hline CRM is entirely aligned with desires of different participants & 0.773 & & & & 2.934 & 1.258 \\
\hline $\begin{array}{r}\text { CRM Strategy is well supported by specific plar } \\
\text { with CRM Strategy t }\end{array}$ & 0.937 & & & & 2.985 & 1.023 \\
\hline $\begin{array}{l}\text { Critical success factor 5: Implementation Approach (IAPT) } \\
\qquad \alpha=0.880\end{array}$ & & 2.967 & 74.185 & 3.658 & & \\
\hline Is CRM Strategy implementation flexible & 0.888 & & & & 3.207 & 1.018 \\
\hline CRM Strategy is broken down & 0.847 & & & & 3.354 & 1.049 \\
\hline Councils has got enough resources $\mathrm{t}$ & 0.709 & & & & 2.774 & 1.220 \\
\hline $\begin{array}{c}\text { Mayor and other Top Managers of the local councils support CRM Stra } \\
\text { implementation }\end{array}$ & 0.523 & & & & 3.604 & 0.963 \\
\hline Critical success factor 6: Metrics (MET) $\alpha=0.825$ & & 2.725 & 68.116 & 0.564628 .181 & & \\
\hline Key Performance Indicators (KPI's) are available to measure CRM success & .216 & & & & 3.590 & 0.692 \\
\hline CRM process are known and procedures are clearly demarcated & 0.851 & & & & 3.261 & 0.976 \\
\hline CRM process are continually enhanced by performance measurement tools & 0.863 & & & & 3.133 & 0.936 \\
\hline CRM expectations are set for all parties involved prior to CRM Strategy implementation & 0.794 & & & & 3.170 & 0.921 \\
\hline Critical success factor 7: Implementation Strategy (IMST) $\alpha=0.545$ & & 3.274 & 81.850 & 0.759785 .449 & & \\
\hline CRM systems are integrated & 0.925 & & & & 3.010 & 1.305 \\
\hline All stakeholders are consulted and involved during CRM Strategy implementation & 0.853 & & & & 3.102 & 1.055 \\
\hline CRM Strategy implementation is championed by one department in councils & 0.623 & & & & 3.558 & 1.310 \\
\hline $\begin{array}{l}\text { CRM Strategy implementation guidelines, and processes are easily available for all } \\
\text { stakeholders }\end{array}$ & 0.873 & & & & 3.173 & 0.756 \\
\hline Critical success factor 8: Buy-in \& Adoption (BIAT) $\alpha=-0.041$ & & 1.954 & 48.842 & 0.541196 .844 & & \\
\hline Mayor and Top Managers are actively involved in adopting CRM Strategy & 0.799 & & & & 4.162 & 0.688 \\
\hline $\begin{array}{l}\text { Employees are motivated by incentives and rewards to encourage a customer centric } \\
\text { behaviour }\end{array}$ & 0.834 & & & & 3.462 & 1.276 \\
\hline Training is provided to employees and other CRM users prior to CRM implementation & 0.805 & & & & 3.036 & 1.002 \\
\hline Employee resistance to new CRM technology is common & 0.800 & & & & 3.940 & 0.831 \\
\hline Critical success factor 9: Project Management (PMT) $\alpha=0.950$ & & 2.727 & 90.887 & 0.770584 .319 & & \\
\hline CRM team has got well qualified staff & 0.925 & & & & 3.360 & 1.043 \\
\hline CRM budget is adequately resourced & 0.896 & & & & 2.848 & 1.248 \\
\hline CRM team is fairly represented by all departments of the council & 0.905 & & & & 3.533 & 1.100 \\
\hline Critical success factor 10: Process Design (PDT) $\alpha=0.827$ & & 2.694 & 67.350 & 0.589518 .702 & & \\
\hline CRM processes are customer centric & 0.529 & & & & 4.223 & 0.418 \\
\hline CRM process are consistent by setting tangible and me & 0.850 & & & & 3.411 & 0.820 \\
\hline CRM process are user friendly & 0.833 & & & & 3.965 & 0.759 \\
\hline CRM processes are constantly improved by performance measurement tools & 0.682 & & & & 3.345 & 0.876 \\
\hline
\end{tabular}


shows psychometric equivalence by providing acceptable levels of reliability, variance extracted, and both discriminant and nomological validity. All factor loadings used in this research had a statistical significance of 0.01 level and exceeded the arbitrary 0.5 standard. Therefore, these measures establish adequate convergent validity. Generally, these results provide support for construct validity for the measures included in this study. As shown in Table 1, the estimated standard loadings ranged from $0.50-0.92$ and are above the normally acceptable cut-off value of 0.50 (Teo and King, 1996). Lastly, all items loaded higher on their respective constructs than on others, thus providing strong support for discriminant validity. The validity of the scale thus elucidates the unidimensionality of the components of each scale (Gerbing and Anderson, 1998) with a principal component factor analysis. These discoveries therefore reduce the plausibility of threat to validity in this study, by presenting a description of CRM construct and explicative CRM framework model for local government authorities, grounded on the CRM concept. The results in Table 1 exhibit that the measurement items of CSFs in CRM Strategy have complete psychometric properties. Also as confirmed by the results of this research, all the measurement items were above 0.50 , meaning that the items are reliable to measure the CSFs in CRM Strategy in the LGAZ. The tool thus used, therefore displays both conceptual and psychometric uniformity by providing satisfactory levels of consistency and validity of the results. In conclusion, the verdicts of this study will therefore augment to theory growth and optimistically enhanced service delivery performance of the LGAZ and in Africa as a whole. Strategically, the CSFs in a CRM Strategy measurement scale can be employed to appraise the effectiveness of the CRM Strategy of local government authorities' efficiency as a reference point measure. In this study all measurement items of the instrument were fulfilled using factor analysis.

\section{CONCLUSION AND RECOMMENDATIONS}

This study examined the psychometric properties and the stability of the factor structure of CRM scale items in the LGAZ. The findings verified that CSFs in CRM scale items in Zimbabwe have comprehensive psychometric properties and a dependable factor structure. Even though further investigations are welcome to replicate the current findings and provide supplementary evidence of the psychometric competence. The Zimbabwean version of CRM scale items is thus postulated to be an excellent tool for the assessment of CRM performance of local government authorities. Therefore, the instrument shows both conceptual and psychometric equivalence by providing satisfactory levels of reliability, variance extracted and both discriminant and nomological validity. The instrument in this empirical research will consequently contribute to theory development and enhance CRM execution and performance of the LGAZ. From a managerial viewpoint, the CRM scale can be applied in evaluating the critical factors desirable concerning the victory of CRM Strategy success in the local government authorities.

\section{REFERENCES}

Babin, J. B. and Svensson, G, (2012). Structural equation modeling in social science research process, European Business Review, 24(4), 320-330. https://doi.org/10.1108/ 09555341211242132

Bagozzi, R. P. and Foxall, G. R. (1995). Construct validity and generalizability of the kirton adaption-innovation inventory. European Journal of Personality, 9(3), 185-206. https://doi.org/10.1002/per.2410090303

Bearden, W. O. and Netemeyer, R. G (1999). Handbook of Marketing scales: Multi item measures for marketing and Consumer Behaviour research, Sage, Newsbury Park, CA.

Blankson, C. and Cheng, J. M. S, (2005). Have small business adopted Market orientation concept? The case of small business in Michigan. Journal of Business and Industrial Marketing, 20(60), 317-330. https://doi.org/10.1108/ 08858620510618156

Blankson, C. and Stokes, D, (2002). Marketing practices in the UK small businesses sector. Marketing Intelligence and Planning, 20(1), 49-61. https://doi.org/10.1108/02634500 210414774

Churchill, G. A. Jr. (1979) A paradigm for developing better measures of marketing constructs. Journal of Marketing Research, 16, 64-73. https://doi.org/10.2307/3150876

Gerbing, D. W. and Anderson, J. C, (1988). An updated paradigm for scale development incorporating unidimensionality and its assessment, Journal of Marketing Research, 25, 186-192. https://doi.org/10.2307/3172650

Gilliam, D. A. and Voss, K (2013). A proposed procedure for construct definition in marketing, European Journal of Marketing, 47(1/2), 5-26. https://doi.org/10.1108/ 03090561311285439

Hunt, S. D, (1991). Modern marketing theory, Critical Issues in the Philosophy of Marketing Science. Cincinnati, Ohio: South Western Publishing Company.

Jaiyeoba, O. O. (2013). Revisiting the Psychometric Properties of Market Orientation Framework in an Emerging Economy: a Case-Study of Botswana's Small Service Firms. Business and Economic Research, 3(2), 236.

Jaworski, B. J. and Kholi, A. K, (1993). Market orientation antecedents and consequences. Journal of Marketing, 57(30), 53-70. https://doi.org/10.2307/1251854

Mackenzie, S. B. (2003). The dangers of poor constructs conceptualization, Journal of the Academy of Marketing Science, 31(3), 323-326. https://doi.org/10.1177/ 0092070303031003011

Mowen, J. C. and Voss, K. E. (2008). On building better construct measures: Implications of a general hierarchical model: Psychology and Marketing, 25(6), 485-505. https://doi.org/10.1002/mar.20221

Nunnally, J. C. (1978). Psychometric Theory. New York: Mc Graw-Hill, Publishing.

Rossiter, J. R. (2002). The C-OAR-SE procedure for scale development in marketing, International Journal of Research in Marketing, 19(4), 305-335. https://doi.org/ 10.1016/S0167-8116(02)00097-6 
Rust, R. T. and Cooil, B. (1994). Reliability measures for qualitative data: theory and implications. Journal of Marketing Research, 31, 1-15. https://doi.org/10.2307/ 3151942

Summers, J. O. (2001). Guidelines for conducting research and publishing in marketing: from conceptualization through the review process. Journal of the Academy of Marketing Science, 29(4), 405-415. https://doi.org/10.1177/ 03079450094243
Teas, R. K. and Palan, K. M (1997). The realms of scientific meaning framework for constructing theoretically meaningful nominal definitions of marketing concepts. Journal of Marketing, 61(2), 52-67.

Teo, TSH., and King W. R., (1996). Key dimensions of facilitators and inhibitors for the strategic use of information technology. Journal of Management information systems, 12(4), 35-53. https://doi.org/10.2307/ 1251830

Williamson, T. (1994). Vagueness. London: Routledge. 